\title{
Colorless-to-colorful switching of electrochromic MXene by reversible ion insertion
}

\author{
Jianxia Jiang ${ }^{1,2}$, Leiqiang Qin² $(\bowtie)$, Joseph Halim², Per O. Å. Persson², Lintao Hou' $(\bowtie)$, and Johanna Rosen ${ }^{2}(\bowtie)$ \\ ${ }^{1}$ Guangzhou Key Laboratory of Vacuum Coating Technologies and New Energy Materials, Physics Department, Jinan University, Guangzhou \\ 510632, China \\ ${ }^{2}$ Department of Physics, Chemistry and Biology (IFM), Linköping University, Linköping SE-58183, Sweden
}

(C) The Author(s) 2021

Received: 29 July 2021 / Revised: 2 September 2021 / Accepted: 29 September 2021

\begin{abstract}
Electrochromic (EC) materials that change color with voltage have been widely studied for use in dynamic windows. However, colorless-to-colorful switching with high contrast ratio is generically unattainable, especially for colorless-to-black electrochromic materials with an ultrahigh contrast ratio over the entire visible region. In this work, we developed $\mathrm{Nb}_{1.33} \mathrm{C}$ MXene-based dynamic windows with colorless-to-black switching of up to $75 \%$ reversible change in transmittance from 300 to $1,500 \mathrm{~nm}$. By exploring the electrochromic effects of different electrolytes through in situ optical changes and electrochemical quartz crystal microbalance $(E Q C M)$, it is found that electrochromic behavior is greatly influenced by the extent of reversible $\mathrm{Li}^{+}$ insertion/deinsertion between the two-dimensional $\mathrm{Nb}_{1.33} \mathrm{C}$ MXene nanosheets. In addition, a colorless-to-black EC device based on $\mathrm{Nb}_{1.33} \mathrm{C}$ with an overall integrated contrast ratio over $80 \%$ was successfully constructed by a solution-processable spin coating method. This work enables a simple route to fabricate MXene-based high-performance electrochromic smart windows, which is important for further expanding the application of MXenes to optoelectronic and photonic applications.
\end{abstract}

\section{KEYWORDS}

MXenes, electrochromic materials, colorless-to-black switching, high contrast ratio, reversible $\mathrm{Li}^{+}$insertion

\section{Introduction}

As smart windows can allow dynamic controlling, tuning and optimizing the ingress and egress of light to flow through buildings and motor vehicles, they have attracted more attention over the world [1-3]. Altering the optical or thermal properties of windows will not only significantly reduce the energy consumption in lighting, heating and air conditioner cooling systems by up to $40 \%$, but also improve the esthetics of interior spaces. Therefore, it is important to develop light-adjusting devices to control and modulate light transmittance of windows with the reduction in energy consumption, versatile colors and fast switching properties [4-6].

Many research efforts have focused on the production of electrochromic materials (ECMs), such as transition metal oxides [7], polymers [8,9], and small organic molecules [10]. Tungsten oxide $\left(\mathrm{WO}_{3}\right)$ is a widely studied inorganic ECM because its superior optical memory and cyclic as well as environmental stability can meet commercial requirements [11,12]. Polythiophenes and their derivatives with low-power consumption, facile color tunability through molecular design, and high processability of highly flexible are among the most promising conjugated polymers for the manufacture of electrochromic (EC) devices [13-16]. However, because the design of completely reversible absorptions in transmissive and colored states is extremely difficult, the colorless-to-colorful ECMs, especially the colorless-to-black ECMs with ultrahigh contrast ratio in the entire visible spectrum, are still challenging to achieve [17]. Therefore, until now it is still hard for electrochromic smart windows to replace traditional curtains for providing a private environment, and most of them are used in dimmable architectural windows.

In 2011, a new family of two-dimensional (2D) metal carbides and/or nitrides with metallic conductivity and hydrophilic surfaces was reported. These novel 2D materials are labeled MXenes, which means that they are prepared by etching the A layers in the layered $M n+1 A X n$ phase $[18,19]$. MXenes have already shown great potential for applications in, e.g., energy storage [20-22], electromagnetic interference shielding $[23,24]$, and transparent conductors [25]. In 2017, a new type of MAX phase was reported $\left.\left(\mathrm{Mo}_{2 / 3} \mathrm{Sc}_{1 / 3}\right)_{2} \mathrm{AlC}\right)$, with in-plane chemical ordering for the two $\mathrm{M}$-elements, hence it is referred to as $i$-MAX [26]. After selective etching of $\mathrm{Sc}$ and $\mathrm{Al}, \mathrm{a} \mathrm{Mo}_{1.33} \mathrm{C}$ MXene with ordered vacancies was achieved, displaying superior volumetric capacitance and high conductivity. Inspired by the above results, a series of $i$-MAX phases and their 2D counterpart, either with in-plane chemical ordering or ordered vacancies, were reported [27-30]. Also formation of disordered vacancies in an $\mathrm{Nb}_{1.33} \mathrm{C}$ MXene was obtained through selective etching of a solid solution MAX phase, $\left(\mathrm{Nb}_{0.67} \mathrm{Sc}_{0.33}\right)_{2} \mathrm{AlC}$ [31].

It is generally accepted that the EC phenomenon based on transition metals can be attributed to the injection/extraction of electrons and ions. EC performance usually depends on the electron transport efficiency of the ECMs and the reversible solid phase diffusion of ions in the EC films. Therefore, MXenes, with 
high conductivity for electron transport and with a highly-specific surface area could be excellent potential candidates for ECMs. Thus far, however, there are few reports on the use of MXenes for ECMs, focusing on $\mathrm{Ti}_{3} \mathrm{C}_{2}$ MXenes only, likely due to poor performance shown and a lack of explanation for these results. This provides a rationale to go beyond previously explored MXenes, and also explore the effect of introduction of vacancies.

In this research, we developed EC smart windows based on the $\mathrm{Nb}_{1.33} \mathrm{C}$ MXene using a spin coating method. The electrochromic property of $\mathrm{Nb}_{1.33} \mathrm{C}$ was investigated by in situ spectroelectrochemical characterization with uniform switching between colorless and colorful black states over the entire visible region. The results from electrochemical quartz crystal microbalance (EQCM) and Raman spectroscopy indicate reversible lithium-ion intercalation is related to the electrochromic behavior of $\mathrm{Nb}_{1.33} \mathrm{C}$ MXene. Finally, the excellent performance for the colorless-to-black EC device based on $\mathrm{Nb}_{1.33} \mathrm{C}$ MXene with the contrast ratio up to $80 \%$ was achieved.

\section{Experimental}

\subsection{Preparation of the $\mathrm{Nb}_{1.33} \mathrm{C}$ MXene}

Powders of $\left(\mathrm{Nb}_{2 / 3} \mathrm{Sc}_{1 / 3}\right)_{2} \mathrm{AlC}$ were synthesized by a solid state reaction of elemental powders as previously demonstrated [15]. Powders of $\mathrm{Nb}, \mathrm{Sc}, \mathrm{Al}, \mathrm{C}$ were placed in an agate mortar with a 4/3:2/3:1:1 molar ratio and manually mixed. The mixture was heated at a rate of $5{ }^{\circ} \mathrm{C} \cdot \mathrm{min}^{-1}$ to $1,400{ }^{\circ} \mathrm{C}$ and held for $2 \mathrm{~h}$. After furnace cooling, the lightly sintered sample was crushed with the agate mortar and pestle and sieved through a 450-mesh sieve. $\mathrm{Nb}_{1.33} \mathrm{C}$ MXene was synthesized by selectively etching Sc and Al. Briefly, $1 \mathrm{~g}$ of $\left(\mathrm{Nb}_{2 / 3} \mathrm{Sc}_{1 / 3}\right)_{2} \mathrm{AlC}$ was added to a Teflon bottle containing $20 \mathrm{~mL} 48 \% \mathrm{HF}$ and stirred for $24 \mathrm{~h}$ at room temperature (RT). The acid was removed by washing with deionized (DI) water for several cycles, multilayer MXene was delaminated to a single layer or few layers of $\mathrm{Nb}_{1.33} \mathrm{C}$ MXene by intercalating with $\mathrm{TBAOH}$. The concentration of $\mathrm{Nb}_{1.33} \mathrm{C}$ solution was measured by filtering a known volume of colloidal dispersion through a polypropylene filter (3501 Coated PP, $0.064 \mu \mathrm{m}$ pore size, Celgard LLC, USA), followed by overnight drying under vacuum and weighing.

\subsection{Preparation of $\mathrm{Nb}_{1.33} \mathrm{C}$ transparent film}

The transparent thin films were fabricated by a spin-coating approach. The substrates of indium tin oxide (ITO) were cleaned by detergent and followed by TL-1 treatment. Then $30 \mu \mathrm{L}$ delaminated $\mathrm{Nb}_{1.33} \mathrm{C}$ colloidal solution $\left(15 \mathrm{mg} \cdot \mathrm{mL}^{-1}\right)$ was pipetted onto the substrate, which was fastened to the rotating plate of a spin-coater. By varying the spinning speed (ranging from 1,000 to 4,000 rpm), we controlled the film thickness, and in turn the transmittance. The obtained thin films were kept in a vacuum desiccator overnight before characterization.

\subsection{EC device fabrication}

For the preparation of gel electrolyte of EC device, we mixed poly(methyl methacrylate) $(10 \mathrm{kDa})$ and $\mathrm{LiClO}_{4}$ (with a molar ratio of 10:1) and dissolved them in $25 \% \mathrm{w} / \mathrm{v}$ acetonitrile. The acetonitrile solvent was stirred and evaporated at $80{ }^{\circ} \mathrm{C}$ before gelation. The polydimethylsiloxane (PDMS) as a frame was placed on the ITO and the gel electrolyte was dropped within the PDMS frame. Then the MXene coated ITO glass was placed face-down on the gel-coated slide and the two electrodes were pressed together. Finally, ultraviolet (UV) curing glue was dripped on the edge of the device and cured for $60 \mathrm{~s}$ under a $256 \mathrm{~nm}$ UV lamp.

\subsection{Characterization}

The zeta potential and dynamic light scattering of $\mathrm{Nb}_{1.33} \mathrm{C}$ MXene was tested using a Zetasizer ZEN3600 (Malvern Instruments Ltd., UK). Scanning electron microscopy (SEM) imaging was performed using a SEM LEO 1550 Gemini operated with an acceleration voltage at $5 \mathrm{keV}$. Scaning transmission electron microscope (STEM) was combined with high angle annular dark field imagining (STEM-HAADF) in a double-corrected Linköping FEI Titan360-300, operated at both 300 and $60 \mathrm{kV}$. X-ray diffraction (XRD) was carried out on a PANalytical X'Pert powder diffraction with $\mathrm{Cu}$ source $\left(\lambda_{\mathrm{K} \alpha} \approx 1.54 \AA\right.$ ). Graded BraggBrentano with a $1 / 4^{\circ}$ divergent and $1 / 2^{\circ}$ anti-scatter slits, and a 5 $\mathrm{mm}$ anti-scatter slit together with a Soller slit (with an opening of 0.04 radian) in the incident and the diffracted beam sides were used, respectively. The optical spectra of the MXene thin films were measured in the range of $300-1,500 \mathrm{~nm}$ by ultraviolet-visible-near infrared ray (UV-vis-NIR) spectroscopy (LAMBDA 950, Perkin Elmer). Atomic force microscopy (AFM) was performed at ambient conditions (room temperature in a lab) using a Veeco DI Dimension 3100 scanning probe microscope, equipped with the nanoscope IV electronics. The measurements were performed in tapping mode using $\mathrm{Si}$ tips (PPPNCHR-50 from Nanosensors) with a tip radius of curvature $<7 \mathrm{~nm}$. The thicknesses of spin-coated films were determined with a Bruker Stylus Profiler (Model: Dektak XT). Raman spectroscopy was done using an inverted reflection mode with a Renishaw microscope (2008, Glouceshire, UK), equipped with $50 \times$ objective and a LEICA CTR6000 setup with $532 \mathrm{~nm}$ laser, 1,800 lines. $\mathrm{mm}^{-1}$, grated at $10 \%$ of maximum intensity. Electrochemical experiments were performed using autolab PGSTAT30 MBA.

\section{Results and discussion}

\subsection{Synthesis and characterization of $\mathrm{Nb}_{1.33} \mathrm{C}$ MXene} film

The $2 \mathrm{D} \mathrm{Nb}_{1.33} \mathrm{C}$ MXene was synthesized by etching a laminated solid solution $\left(\mathrm{Nb}_{2 / 3} \mathrm{Sc}_{1 / 3}\right)_{2} \mathrm{AlC}$ MAX phase for removal of both the $\mathrm{Sc}$ and $\mathrm{Al}$ atoms. The target MXene with hydrophilic surface can be easily processed in aqueous solvents to form a colloidal solution at room temperature through intercalation and delamination using TBAOH. The synthesized $\mathrm{Nb}_{1.33} \mathrm{C}$ colloidal dispersion has the Tyndall effect and exhibits inherent colloidal stability caused by negative surface charges (Fig. S1 in the Electronic Supplementary Material (ESM)). The lateral size distribution of the $\mathrm{Nb}_{1.33} \mathrm{C}$ single sheets in the colloidal solution is concentrated at the range 0.5-2 $\mu \mathrm{m}$ (Fig. 1(a) and Fig. S2 in the ESM) and the thickness of the flakes is around $2 \mathrm{~nm}$, according to the AFM measurements in Fig. 1(b). The hydrophilic surface of MXene makes it solution processable, allowing formation of MXene films through a variety of techniques, such as vacuum assisted filtration, spray, spin, or dip coating [32-35]. In order to meet the requirements of transparent electrodes for smart windows, MXene films obtained by spin-coating are chosen for this work, which could yield smooth and transparent films on any substrates, such as conductive or nonconductive and even flexible substrates (Fig. $\mathrm{S} 3$ in the ESM). The XRD patterns of the etched materials show the typical increase in the interlayer spacing compared to the parent phase. This is a typical phenomenon of the conversion from MAX phase to MXene which reflects the replacements of Sc and $\mathrm{Al}$ by the surface terminations of $-\mathrm{O},-\mathrm{OH}$, and/or $-\mathrm{F}$ and presence of water layers $[19,36,37]$. Compared with the $\mathrm{Nb}_{1.33} \mathrm{C}$ paper obtained by vacuum filtration, the layer spacing of the film obtained by spin coating increased from 14.3 to $19.6 \AA$ (Fig. 1(c)), 

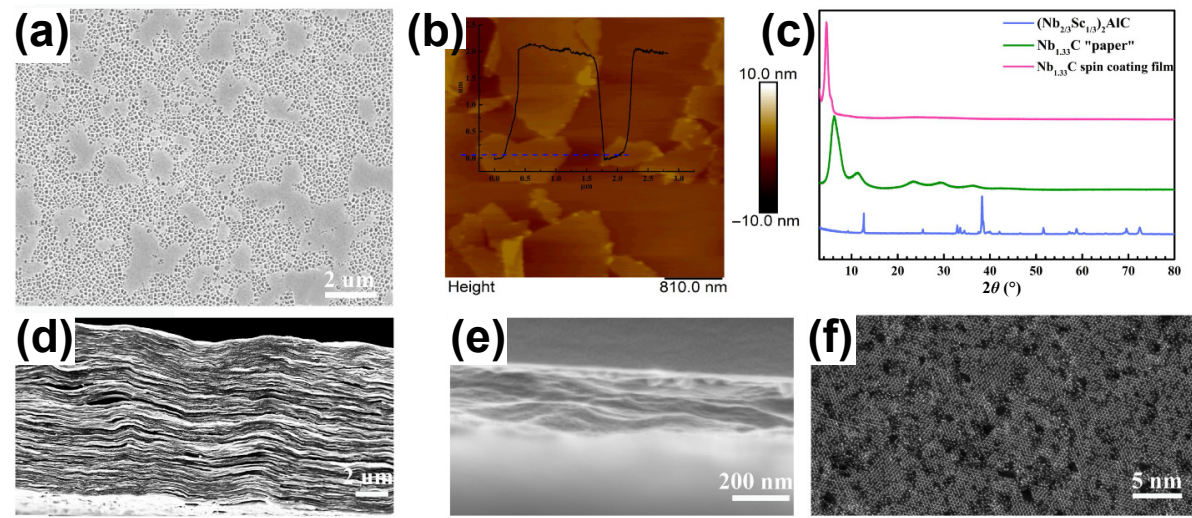

Figure 1 (a) SEM and (b) AFM imges of $\mathrm{Nb}_{1.33} \mathrm{C}$ nanosheets; (c) XRD patterns of the $\left(\mathrm{Nb}_{2 / 3} \mathrm{Sc}_{1 / 3}\right)_{2} \mathrm{AlC}$ powder, $\mathrm{Nb}_{1.33} \mathrm{C}$ paper and $\mathrm{Nb}_{1.33} \mathrm{C}$ film spin coated on ITO; cross section images of (d) $\mathrm{Nb}_{1.33} \mathrm{C}$ paper and (e) a $\mathrm{Nb}_{1.33} \mathrm{C}$ film (middle) spin coated on ITO (top); (f) higher magnification STEM micrograph of $\mathrm{Nb}_{1.33} \mathrm{C}$ single flake.

which is consistent with the less compact structure from crosssectional SEM images (Figs. 1(d) and 1(e)). The relatively loose arrangement of $\mathrm{Nb}_{1.33} \mathrm{C}$ nanosheets will facilitate the insertion and extraction of ions in the spin-coated MXene film. In addition, as seen from the STEM images, it can be found that the $\mathrm{Nb}_{1.33} \mathrm{C}$ flakes contain vacancies and local clusters thereof, in size ranging between 0.1 and $2 \mathrm{~nm}$ (Fig. 1(f)). These additional vacancies may provide channels for ion transport.

\subsection{In situ electrochemical and optical characterization of $\mathrm{Nb}_{1.33} \mathrm{C}$ thin films}

As shown in Fig. 2(a), the cyclic voltmetric (CV) curve of the $\mathrm{Nb}_{1.33} \mathrm{C}$ film is recorded within the potential range from 1.3 to $5.3 \mathrm{~V}$ vs. $\mathrm{Li} / \mathrm{Li}^{+}$at scan rate of $20 \mathrm{mV} \cdot \mathrm{s}^{-1}$. The $\mathrm{CV}$ curve shows an obvious oxidation and reduction couple from 3.3 to $1.3 \mathrm{~V}$. Spectroelectrochemical studies of spin-coated $\mathrm{Nb}_{1.33} \mathrm{C}$ films on ITO were performed in an electrochemical cell with commercial UV-visible cuvette to evaluate the electrochromic properties. The electro-optical properties of $\mathrm{Nb}_{1.33} \mathrm{C}$ films were studied by in situ UV-vis-NIR spectroscopy with propylene carbonate (PC) containing $1 \mathrm{M} \mathrm{LiClO}_{4}$ as an electrolyte. The spectroelectrochemistry of $\mathrm{Nb}_{1.33} \mathrm{C}$ film upon reduction was reflected by a series of UV-vis-NIR absorbance curves, which were changed under various applied potentials, as shown in Fig. 2(b). The corresponding colors of the spin-coated film are related to the different electrode potentials. The $\mathrm{Nb}_{1.33} \mathrm{C}$ film possesses initial low absorbance across the visible to infrared spectrum. Stepwise reduction of the $\mathrm{Nb}_{1.33} \mathrm{C}$ film from 5.3 to $1.3 \mathrm{~V}$ vs. $\mathrm{Li} / \mathrm{Li}^{+}$causes an increase in absorbance over the entire wavelength range, especially when the potential drops to $1.7 \mathrm{~V}$. This is consistent with the onset reduction potential in the $\mathrm{CV}$ curve. Moreover, the absorbance profile during switching is relatively flat over the entire visible spectrum, which gives rise to an esthetically pleasing clear-to-greyto-black transition. Therefore, the corresponding color of $\mathrm{Nb}_{1.33} \mathrm{C}$ film is visible transparency in the oxidized state (Fig. 2(b), top left inset) and black in the reduced state (Fig. 2(b), top right inset). Furthermore, the absorbance spectra demonstrate that the window also effectively modulates infrared light, which makes it useful for controlling the flow of heat in and out of spaces such as buildings and motor vehicles.

The optical switching is qualitatively evidenced by applying a square wave potential-step coupled with optical spectroscopy in PC containing $1 \mathrm{M} \mathrm{LiClO}_{4}$. The electrochromic parameters, such as optical contrast ratio $(\Delta T \%)$, response time and coloration efficiency of the $\mathrm{Nb}_{1.33} \mathrm{C}$ films were investigated by switching the transmittance with respect to potentials at the specific absorption wavelength of 700 or $1,200 \mathrm{~nm}$, as shown in Fig. 3 (summarized in Table S1 in the ESM). Based on the CV data, the electrochemical potentials used for the coloration/bleach conversion were selected to ensure the reduction and oxidation reactions (Fig. 2(a)). Therefore, the color switching was qualitatively evidenced by applying a square wave potential between 5.3 and $1.3 \mathrm{~V}$ vs. $\mathrm{Li}^{2} / \mathrm{Li}^{+}$ at high frequency of $0.01 \mathrm{~Hz}$. For $\mathrm{Nb}_{1.33} \mathrm{C}$, a reversible oscillation between black and colorless states was observed. The optical contrast ratios of $\mathrm{Nb}_{1.33} \mathrm{C}$ between colored state at $1.3 \mathrm{~V}$ and bleached state at $5.3 \mathrm{~V}$ are $75.0 \%$ at $700 \mathrm{~nm}$ and $68.1 \%$ at 1,200 $\mathrm{nm}$ (Figs. 3(a) and 3(b)), respectively. It is worth noting that the $\mathrm{Nb}_{1.33} \mathrm{C}$ films have very high integrated contrast ratios in both the visible and infrared regions, making them suitable not only for truly smart curtains, but also to control the temperature by adjusting infrared light in and out.

\subsection{Understanding the mechanism involved in electrochromic changes}

Currently, the most well-developed electrochromic technology is based on intercalation/deintercalation of small ions in electrode materials. Among the best known representatives is $\mathrm{WO}_{3}$, which has already been commercialized and appears in our daily
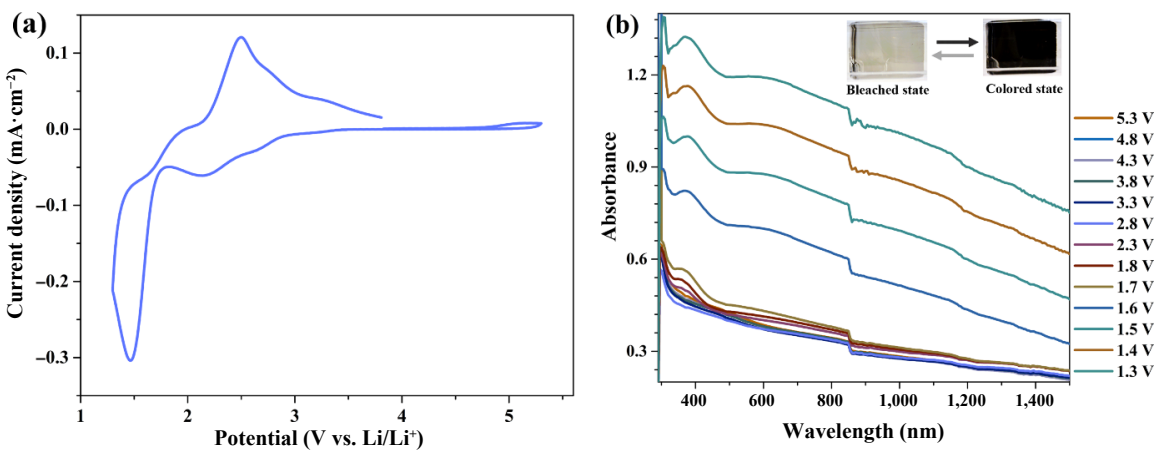

Figure 2 (a) CV of the electrochromic $\mathrm{Nb}_{1.33} \mathrm{C}$ MXene on ITO at $20 \mathrm{mV} \cdot \mathrm{s}^{-1}$. (b) Absorption spectra of the electrochromic $\mathrm{Nb}_{1,33} \mathrm{C}$ MXene on ITO at different redox states. Inset: the images of the $\mathrm{Nb}_{1.33} \mathrm{C}$ film at bleached state and colored state. 

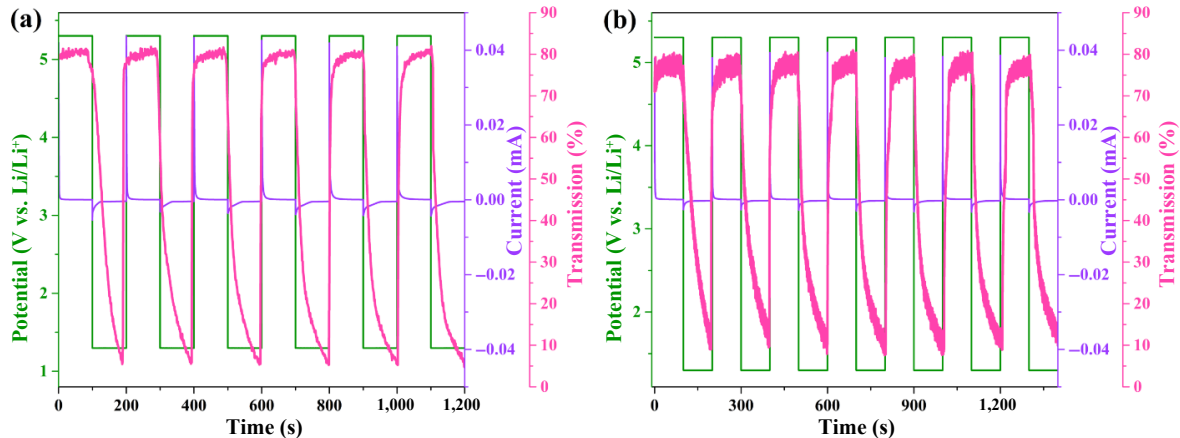

Figure 3 Current evolution (purple curves) upon application of a square wave potential (green curves) and the corresponding in situ measured transmission (red curves) at $700 \mathrm{~nm}$ (a) and 1,200 nm (b) during cycles between 1.3 and $5.3 \mathrm{~V} \mathrm{vs.} \mathrm{Li/Li+} \mathrm{at} 0.01 \mathrm{~Hz}$.

life $[38,39]$. To understand the $\mathrm{EC}$ mechanism of $\mathrm{Nb}_{1.33} \mathrm{C}$ MXene, transmittance changes under different states (Fig. S5 in the ESM), observed from in situ EQCM (Fig. 4), and transmittance changes with time (Fig. 5) were analyzed using different electrolytes. The transmittance of $\mathrm{Nb}_{1.33} \mathrm{C}$ film shows a relatively flat curve in both the colored state and the bleached state at $\mathrm{LiClO}_{4}$ electrolyte, and the integrated contrast ratio almost reaches $75 \%$ (Fig. S5(a) in the ESM). $\mathrm{LiBF}_{4}$ and $\mathrm{NaClO}_{4}$ electrolytes show a similar higher contrast ratio compared with $\mathrm{LiClO}_{4}$ (Figs. S5(b) and S5(c) in the ESM). However, the transmittance of $\mathrm{Nb}_{1.33} \mathrm{C}$ showed no significant difference between the colored state and the bleached state for tetrabutylammonium tetrafluoroborate $\left(\mathrm{TBABF}_{4}\right)$ electrolyte with the very low contrast ratio of $\Delta T \%<10 \%$ (Fig. $\mathrm{S} 5$ (d) in the ESM). From the above results, it seems that cations have a greater impact on the electrochromic properties of $\mathrm{Nb}_{1.33} \mathrm{C}$ than anions.

To corroborate our hypothesis, in situ EQCM was performed within a three-electrode configuration. The triangle wave potential step method was employed for studying anion and cation contributions to the electrochromic properties of $\mathrm{Nb}_{1.33} \mathrm{C}$. According to Sauerbrey's equation (Eq. (S3) in the ESM), frequency response $(\Delta f)$ and the electrode mass $(\Delta m)$ are inversely proportional. The potential scan and simultaneous EQCM response are collected for $\mathrm{Nb}_{1.33} \mathrm{C}$ films processed by four different electrolytes, as shown in Fig. 4 and Fig S6 in the ESM. The potential first started from 3.8 to $1.3 \mathrm{~V}$ and then switched back to $5.3 \mathrm{~V}$. For $\mathrm{LiClO}_{4}$, the frequency shows the same change versus the potential variation. The increase of the electrode mass observed during the negative potential is associated with cation adsorption $\left(\mathrm{Li}^{+}\right)$, while the electrode mass decreases during desorption at positive potentials. In addition, with multiple cycles, the electrode material exhibits a reversible mass change with the potential switch. In addition, from the mass change calculated by the frequency change, we can get that the number of lithium ions inserting into each $\mathrm{Nb}_{1.33} \mathrm{C}$ is 2.83 (Fig. $\mathrm{S} 7$ in the $\mathrm{ESM}$ ). In Fig. 4(b), the mass of the electrode material with $\mathrm{LiBF}_{4}$ electrolyte also shows a reversible change with the switch of the potential, which is similar to $\mathrm{LiClO}_{4}$. However, when the electrolyte is changed to $\mathrm{TBABF}_{4}$ with the same anion as $\mathrm{LiBF}_{4}$, the mass of the electrode gradually increases with multiple cycles, indicating that the anion $\mathrm{TBA}^{+}$is partly trapped in the $\mathrm{Nb}_{1.33} \mathrm{C}$ film and does not migrate out at the positive potential. It must be mentioned that $\mathrm{TBA}^{+}$is used as an intercalant when preparing single layer $\mathrm{Nb}_{1.33} \mathrm{C}$, and negatively charged $\mathrm{Nb}_{1.33} \mathrm{C}$ and positively charged $\mathrm{TBA}^{+}$have a strong interaction, which makes $\mathrm{TBA}^{+}$difficult to migrate out under positive potential, resulting in a continual increase in electrode mass (as shown in Fig. 4(c)). This irreversible ion migration in and out is very detrimental to electrochromism.
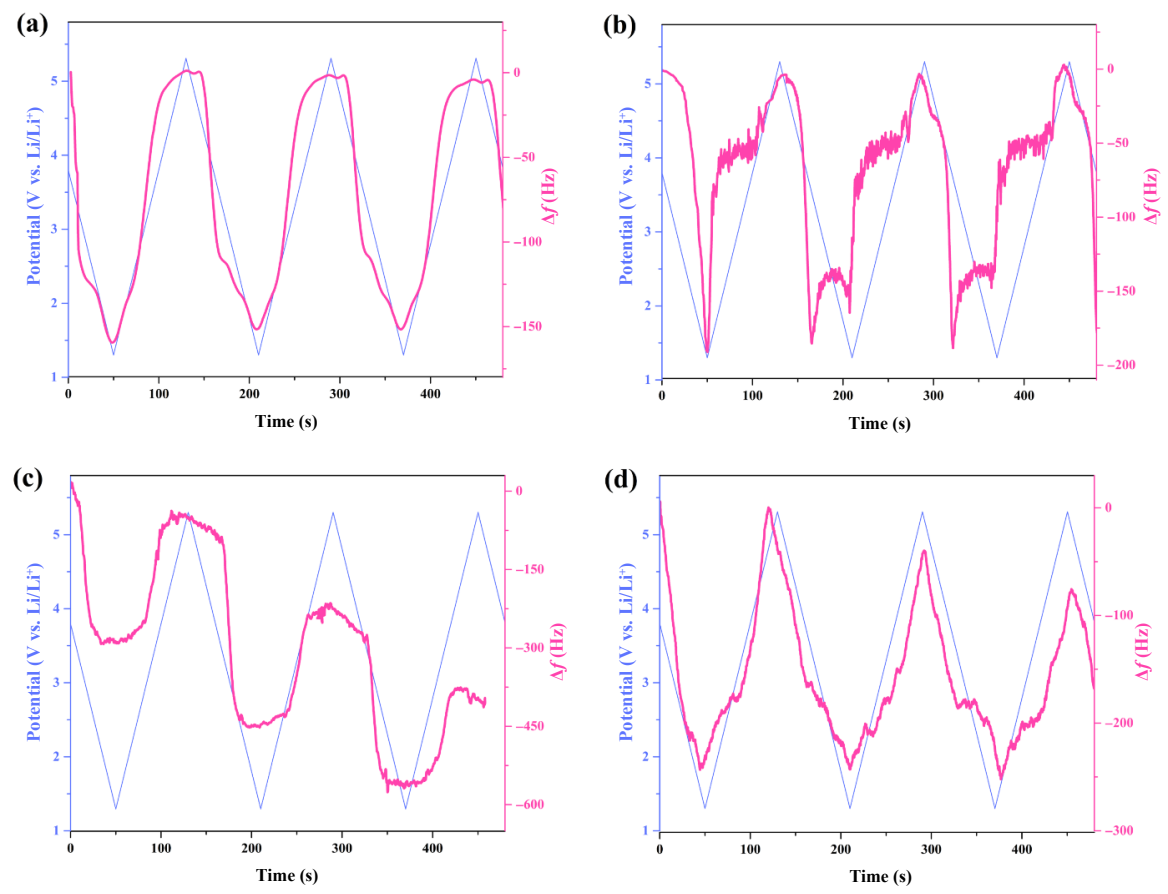

Figure 4 In situ EQCM of $\mathrm{Nb}_{1.33} \mathrm{C}$ electrode using different electrolytes of (a) $\mathrm{LiClO}_{4}$, (b) $\mathrm{LiBF}_{4}$, (c) $\mathrm{TBABF}_{4}$, and (d) $\mathrm{NaClO}_{4}$. 
Finally, we chose $\mathrm{NaClO}_{4}$ with the same anion as $\mathrm{LiClO}_{4}$ but with a different metal cation as the electrolyte. Similar to $\mathrm{LiClO}_{4}$, the increase and decrease of the electrode mass were observed during the negative and positive potentials, respectively (Fig. 4(d)). However, the mass of the electrode is not completely reversible, but slightly increases with the cycle. This shows that a small number of cations $\left(\mathrm{Na}^{+}\right)$are trapped in the electrode material. Based on the results of in situ EQCM, we conducted optical switching in different electrolytes at the absorption wavelength of $700 \mathrm{~nm}$ (Fig. 5). $\mathrm{Nb}_{1.33} \mathrm{C}$ films show the same stable optical switching in the electrolytes containing Li cation (Figs. 5(a) and 5 (b)), but exhibit very low optical contrast ratio in the organic electrolytes ( $\mathrm{TBABF}_{4}$, Fig. 5(c)). In $\mathrm{NaClO}_{4}$, the $\mathrm{Nb}_{1.33} \mathrm{C}$ exhibits higher optical contrast ratio at the beginning, but gradually decreases with the cycle (Fig.5(d)), as the metal cations are captured by the $\mathrm{Nb}_{1.33} \mathrm{C}$ film corresponding to the colored state. Combined with the variations of spectra and mass of $\mathrm{Nb}_{1.33} \mathrm{C}$ films in different electrolytes with potentials, it indicates that the excellent electrochromic performance of $\mathrm{Nb}_{1.33} \mathrm{C}$ is due to the reversible intercalation of $\mathrm{Li}$ cations. To further prove further our preliminary conclusion, in situ electrochemical Raman spectroscopy was performed in a three-electrode configuration in the $\mathrm{LiClO}_{4}$ electrolyte. Figure 6(a) shows the Raman spectra obtained from the $\mathrm{Nb}_{1.33} \mathrm{C}$ film during the coloring process. By applying a cathodic potential from 3.8 to $1.3 \mathrm{~V}$ vs. $\mathrm{Li} / \mathrm{Li}^{+}$, the electrostatic repulsion between adjacent layers in the layered $\mathrm{Nb}_{1.33} \mathrm{C}$ will decrease with increase of lithium content, resulting in the Raman peak $\left(400 \mathrm{~cm}^{-1}\right)$ shifting up to higher wavenumbers. Finally, an obvious broad peak is formed by merging with the peak at $570 \mathrm{~cm}^{-1}$ due to the formation of $\mathrm{Li}_{x} \mathrm{Nb}_{1.33} \mathrm{C}$. Similar Raman results have been reported by lithium intercalated metal oxide [40, 41]. Furthermore, the ex situ XRD was analyzed in the $2 \theta$ region between $3^{\circ}$ and $7^{\circ}$ to probe the lattice expansion or contraction at different applied potentials (Fig. S8 in the ESM). When potentials are applied from 3.8 to $1.3 \mathrm{~V}$, a shift of the peak $\left(2 \theta=4.5^{\circ}\right)$ is observed, corresponding to an increase of the $c$-lattice parameter due to the intercalation of the electrolyte cation.

\subsection{Electrochromic device performance}

To evaluate further the $\mathrm{EC}$ performance of $\mathrm{Nb}_{1.33} \mathrm{C}$ film in a practical application, particularly the potential of this as an absolute opaque "smart" curtain with high integrated contrast ratio of transmittance changes, the $\mathrm{EC}$ device of $\mathrm{Nb}_{1.33} \mathrm{C}$ was fabricated with device architecture of ITO/ $\mathrm{Nb}_{1.33} \mathrm{C} /$ electrolyte/ITO (Fig. 6(b) inset). The transmittance spectra of the device in bleach and colored states are shown in Fig. 6(b), presenting an ultrahigh integrated contrast ratio up to $80 \%$. In the colored state, the transmittance of the device is almost zero. Besides, the EC device at 700 and 1,200 nm after power-off shows excellent performance stability (Figs. 6(c) and 6(d)). In addition, the cycling performance was conducted to examine the durability of the $\mathrm{Nb}_{1.33} \mathrm{C}$-based $\mathrm{EC}$ device by repeated switching test between bleach and colored states at $700 \mathrm{~nm}$ (Fig. 6(e)). After 1,000 coloration-bleaching cycles, the device showed $95.7 \%$ retention of contrast ratio, which demonstrates the excellent stability performance of the EC device during switching operation. It is worth noting that the outstanding performance not only comes from the loosely arranged $\mathrm{Nb}_{1.33} \mathrm{C}$ nanosheets obtained by spin coating, but also related to the negligible traps in the lithium ion intercalation process. The superior performance of the $\mathrm{Nb}_{1.33} \mathrm{C}$ MXene can significantly expand the industrial market for electrochromic smart-window applications from public places to private places, and brings greater flexibility to build facade design, paving the way for further industrial applications.

\section{Conclusions}

In summary, the colorless to colorful $\mathrm{EC} \mathrm{Nb}_{1.33} \mathrm{C}$ MXene was investigated using the dynamic photoelectrochemical test. Electrochromic performance is dependent on the electrolytes, where the optimal performance was observed in the $\mathrm{LiClO}_{4}$ electrolyte $\left(\Delta T_{700 \mathrm{~nm}} \approx 75 \%\right)$ under a three-electrode electrochemical testing setup. The mechanism of the electrochromic behavior was studied by in situ transmittance and EQCM spectroscopy. The reversible lithium ion intercalation plays an
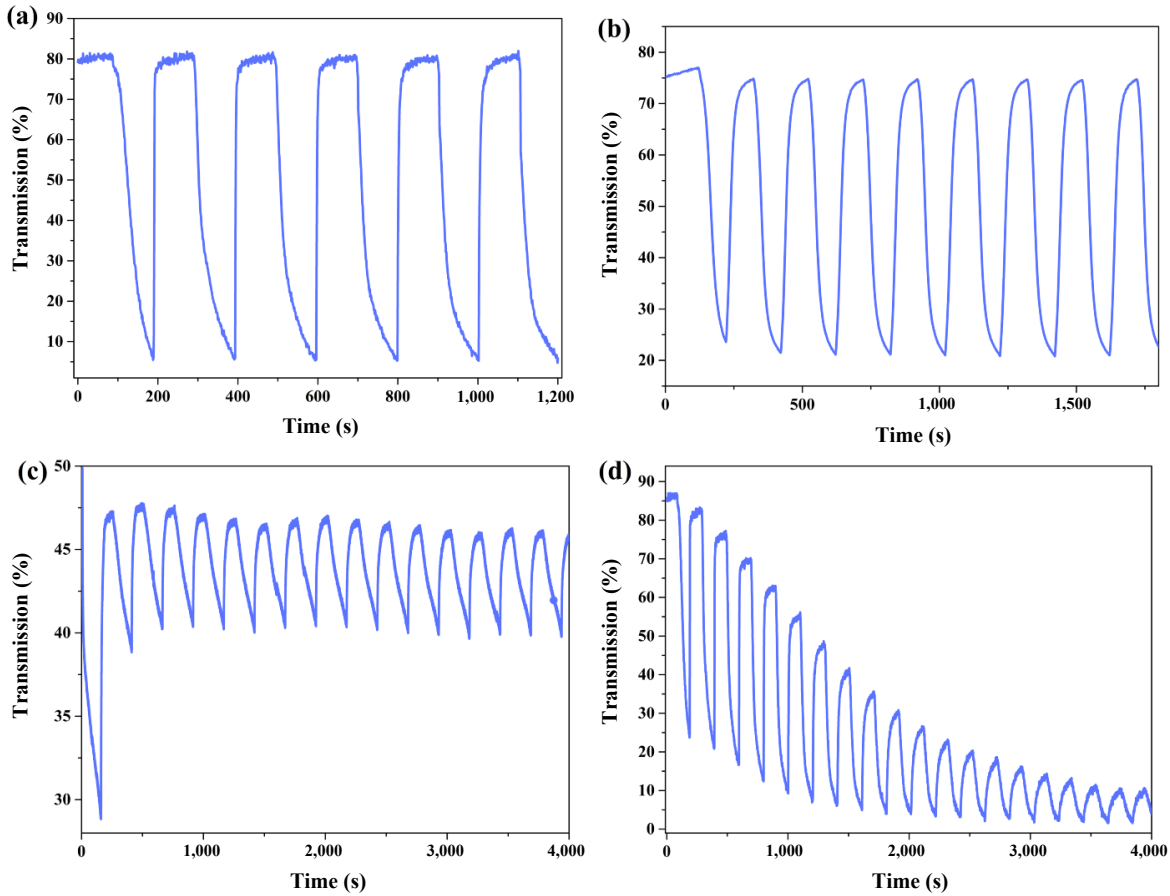

Figure 5 In situ measured transmission at $700 \mathrm{~nm}$ during cycles between 1.3 and $5.3 \mathrm{~V}$ vs. $\mathrm{Li}^{2} \mathrm{Li}^{+}$in different electrolytes of (a) $\mathrm{LiClO}_{4}$, (b) $\mathrm{LiBF}_{4}$, (c) $\mathrm{TBABF}_{4}$, and (d) $\mathrm{NaClO}_{4}$. 

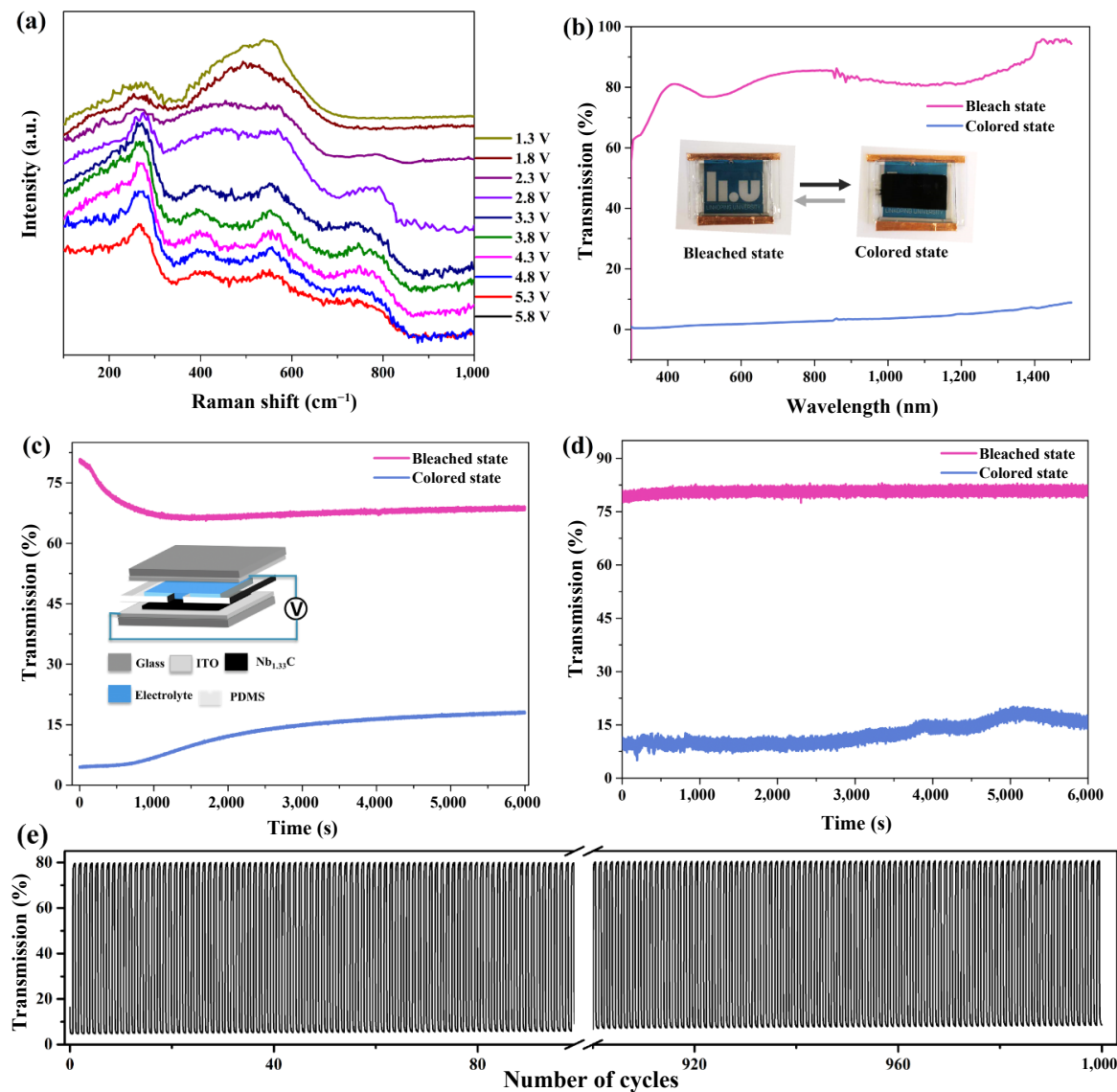

Figure 6 (a) In situ Raman of $\mathrm{Nb}_{133} \mathrm{C}$ at different potentials in $\mathrm{PC}$ with $1 \mathrm{M} \mathrm{LiClO}_{4}$. (b) The $\mathrm{EC}$ device transmittance at different states. Inset: EC device architecture diagram. Transmittance stability of device at $700 \mathrm{~nm}$ (c) and 1,200 nm (d); inset: the images of $\mathrm{Nb}_{1.33} \mathrm{C} \mathrm{EC}$ device at bleached state and colored state. (e) Cyclic stability of $\mathrm{Nb}_{1.33} \mathrm{C}$ electrochromic devices.

important role in EC performance. Furthermore, we demonstrate that the $\mathrm{Nb}_{1.33} \mathrm{C}$-based hybrid dynamic windows uniformly switch between clear and black states with $\sim 80 \%$ optical contrast, and the transmittance of the colored state is almost zero. In addition, the dynamic windows show good transmittance stability in both visible and near infrared regions. This work suggests that MXenebased dynamic window is a promising candidate for the development of new generation electrochromic devices.

\section{Acknowledgements}

This work was financed by the SSF Research Infrastructure Fellow Program (No. RIF 14-0074), the SSF Synergy Program EM16-0004, and by the Knut and Alice Wallenberg (KAW) Foundation through a Fellowship Grant, a Project Grant (No. KAW2020.0033), and for support of the electron microscopy laboratory in Linköping University. Support from the National Natural Science Foundation of China (No. 61774077), the Guangdong Joint Research Fund (No. 2020A1515110738), the Postdoctoral Research Foundation of China (No. 2020M683187), the Key Projects of Joint Fund of Basic and Applied Basic Research Fund of Guangdong Province (No. 2019B1515120073) and the Guangzhou Key laboratory of Vacuum Coating Technologies and New Energy Materials Open Projects Fund (No. KFVE20200006) are also acknowledged.

Funding note: Open access funding provided by Linköping University.

Electronic Supplementary Material: Supplementary material (the zeta potential, DLS of $\mathrm{Nb} 1.33 \mathrm{C}$ and $\mathrm{CV}$ of $\mathrm{Nb} 1.33 \mathrm{C}$ in different electrolytes) is available in the online version of this article at https://doi.org/10.1007/s12274-021-3913-y.

Open Access This article is licensed under a Creative Commons Attribution 4.0 International License, which permits use, sharing, adaptation, distribution and reproduction in any medium or format, as long as you give appropriate credit to the original author(s) and the source, provide a link to the Creative Commons licence, and indicate if changes were made.

The images or other third party material in this article are included in the article's Creative Commons licence, unless indicated otherwise in a credit line to the material. If material is not included in the article's Creative Commons licence and your intended use is not permitted by statutory regulation or exceeds the permitted use, you will need to obtain permission directly from the copyright holder.

To view a copy of this licence, visit http://creativecommons. org/licenses/by/4.0/.

\section{References}

[1] Balaras, C. A.; Droutsa, K.; Dascalaki, E.; Kontoyiannidis, S. Heating energy consumption and resulting environmental impact of European apartment buildings. Energy Build. 2005, 37, 429-442.

[2] Grynning, S.; Gustavsen, A.; Time, B.; Jelle, B. P. Windows in the buildings of tomorrow: Energy losers or energy gainers? Energy Build. 2013, 61, 185-192.

[3] Lee, J. W.; Jung, H. J.; Park, J. Y.; Lee, J. B.; Yoon, Y. Optimization of building window system in Asian regions by analyzing solar heat gain and daylighting elements. Renew. Energy 2013, 50, 522-531.

[4] Granqvist, C. G. Out of a niche. Nat. Mater. 2006, 5, 89-90.

[5] Llordés, A.; Garcia, G.; Gazquez, J.; Milliron, D. J. Tunable near- 
infrared and visible-light transmittance in nanocrystal-in-glass composites. Nature 2013, 500, 323-326

[6] Barile, C. J.; Slotcavage, D. J.; Hou, J. Y.; Strand, M. T.; Hernandez, T. S.; McGehee, M. D. Dynamic windows with neutral color, high contrast, and excellent durability using reversible metal electrodeposition. Joule 2017, 1, 133-145.

[7] Gillaspie, D. T.; Tenent, R. C.; Dillon, A. C. Metal-oxide films for electrochromic applications: Present technology and future directions. J. Mater. Chem. 2010, 20, 9585-9592.

[8] Qin, L. Q.; Xu, J. K.; Lu, B. Y.; Lu, Y.; Duan, X. M.; Nie, G. M. Synthesis and electrochromic properties of polyacrylate functionalized poly(3,4-ethylenedioxythiophene) network films. $J$. Mater. Chem. 2012, 22, 18345-18353.

[9] Qin, L. Q.; Ding, Z. Q.; Hanif, M.; Jiang, J. X.; Liu, L. L.; Mo, Y. Q.; Xie, Z. Q.; Ma, Y. G. Poly(3,4-dioxythiophene) soft nanonetwork with a compatible ion transporting channel for improved electrochromic performance. Polym. Chem. 2016, 7, 6954-6963.

[10] Nguyen, W. H.; Barile, C. J.; McGehee, M. D. Small molecule anchored to mesoporous ITO for high-contrast black electrochromics. J. Phys. Chem. C 2016, 120, 26336-26341.

[11] Hou, R. P.; Li, H.; Diao, M. J.; Sun, Y. H.; Liang, Y.; Yu, Z. Y.; Huang, Z. P.; Zhang, C. Fast electrochemical activation of the broadband saturable absorption of tungsten oxide nanoporous film. Nano Res. , in press, DOI: 10.1007/s12274-021-3478-9.

[12] Zhao, J. M.; Liu, L. T.; Zhang, Y.; Feng, Z. Y.; Zhao, F. F.; Wang, W. S. Light-responsive color switching of self-doped $\mathrm{TiO}_{2-x} / \mathrm{WO}_{3} \cdot 0.33 \mathrm{H}_{2} \mathrm{O}$ hetero-nanoparticles for highly efficient rewritable paper. Nano Res. 2021, 14, 165-171.

[13] Gunbas, G. E.; Durmus, A.; Toppare, L. Could green be greener? Novel donor-acceptor-type electrochromic polymers: Towards excellent neutral green materials with exceptional transmissive oxidized states for completion of RGB color space. Adv. Mater. 2008, 20, 691-695.

[14] Beaujuge, P. M.; Reynolds, J. R. Color control in $\pi$-conjugated organic polymers for use in electrochromic devices. Chem. Rev. 2010, 110, 268-320.

[15] Müllen, K.; Reynolds, J. R.; Masuda, T. Conjugated Polymers: A Practical Guide to Synthesis; RSC Publishing: Cambridge, 2014.

[16] Beaujuge, P. M.; Ellinger, S.; Reynolds, J. R. The donor-acceptor approach allows a black-to-transmissive switching polymeric electrochrome. Nat. Mater. 2008, 7, 795-799.

[17] Shi, P. J.; Amb, C. M.; Knott, E. P.; Thompson, E. J.; Liu, D. Y.; Mei, J. G.; Dyer, A. L.; Reynolds, J. R. Broadly absorbing black to transmissive switching electrochromic polymers. Adv. Mater. 2010, 22, 4949-4953.

[18] Barsoum, M. W. MAX Phases: Properties of Machinable Ternary Carbides and Nitrides; John Wiley \& Sons: Weinheim, 2013.

[19] Naguib, M.; Kurtoglu, M.; Presser, V.; Lu, J.; Niu, J. J.; Heon, M.; Hultman, L.; Gogotsi, Y.; Barsoum, M. W. Two-dimensional nanocrystals produced by exfoliation of $\mathrm{Ti}_{3} \mathrm{AlC}_{2}$. Adv. Mater. 2011, $23,4248-4253$.

[20] Zhang, M.; Cao, J.; Wang, Y.; Song, J.; Jiang, T. C.; Zhang, Y. Y.; Si, W. M.; Li, X. W.; Meng, B.; Wen, G. W. Electrolyte-mediated dense integration of graphene-MXene films for high volumetric capacitance flexible supercapacitors. Nano Res. 2021, 14, 699-706.

[21] Qin, L. Q.; Tao, Q. Z.; Ghazaly, A. E.; Fernandez-Rodriguez, J.; Persson, P. O. Å.; Rosen, J.; Zhang, F. L. High-performance ultrathin flexible solid-state supercapacitors based on solution processable $\mathrm{Mo}_{1.33} \mathrm{C}$ MXene and PEDOT: PSS. Adv. Funct. Mater. 2018, 28, 1703808 .

[22] Ghidiu, M.; Lukatskaya, M. R.; Zhao, M. Q.; Gogotsi, Y.; Barsoum, M. W. Conductive two-dimensional titanium carbide "clay" with high volumetric capacitance. Nature 2014, 516, 78-81.

[23] Shahzad, F.; Alhabeb, M.; Hatter, C. B.; Anasori, B.; Hong, S. M.; Koo, C. M.; Gogotsi, Y. Electromagnetic interference shielding with 2D transition metal carbides (MXenes). Science 2016, 353, $1137-1140$.

[24] Hu, D. W.; Wang, S. Q.; Zhang, C.; Yi, P. S.; Jiang, P. K.; Huang, $\mathrm{X}$. Y. Ultrathin MXene-aramid nanofiber electromagnetic interference shielding films with tactile sensing ability withstanding harsh temperatures. Nano Res. 2021, 14, 2837-2845.

[25] Zhang, C. F.; Nicolosi, V. Graphene and MXene-based transparent conductive electrodes and supercapacitors. Energy Storage Mater. 2019, 16, 102-125.

[26] Tao, Q. Z.; Dahlqvist, M.; Lu, J.; Kota, S.; Meshkian, R.; Halim, J.; Palisaitis, J.; Hultman, L.; Barsoum, M. W.; Persson, P. O. Å. et al. Two-dimensional $\mathrm{Mo}_{1.33} \mathrm{C}$ MXene with divacancy ordering prepared from parent 3D laminate with in-plane chemical ordering. Nat. Commun. 2017, 8, 14949.

[27] Dahlqvist, M.; Lu, J.; Meshkian, R.; Tao, Q. Z.; Hultman, L.; Rosen, J. Prediction and synthesis of a family of atomic laminate phases with Kagomé-like and in-plane chemical ordering. Sci. Adv. 2017, 3, e1700642.

[28] Persson, P. O. Å.; Rosen, J. Current state of the art on tailoring the MXene composition, structure, and surface chemistry. Curr. Opin. Solid State Mater. Sci. 2019, 23, 100774.

[29] Meshkian, R.; Dahlqvist, M.; Lu, J.; Wickman, B.; Halim, J.; Thörnberg, J.; Tao, Q. Z.; Li, S. X.; Intikhab, S.; Snyder, J. et al. Wbased atomic laminates and their $2 \mathrm{D}$ derivative $\mathrm{W}_{1.33} \mathrm{C}$ MXene with vacancy ordering. Adv. Mater. 2018, 30, 1706409.

[30] Persson, I.; el Ghazaly, A.; Tao, Q. Z.; Halim, J.; Kota, S.; Darakchieva, V.; Palisaitis, J.; Barsoum, M. W.; Rosen, J.; Persson, P. O. A. Tailoring structure, composition, and energy storage properties of MXenes from selective etching of in-plane, chemically ordered MAX phases. Small 2018, 14, 1703676.

[31] Halim, J.; Palisaitis, J.; Lu, J.; Thönberg, J.; Moon, E. J.; Precner, M.; Eklund, P.; Persson, P. O. Å.; Barsoum, M. W.; Rosen, J. Synthesis of two-dimensional $\mathrm{Nb}_{1.33} \mathrm{C}$ (MXene) with randomly distributed vacancies by etching of the quaternary solid solution $\left(\mathrm{Nb}_{2 / 3} \mathrm{Sc}_{1 / 3}\right)_{2} \mathrm{AlC}$ MAX phase. ACS Appl. Nano Mater. 2018, 1, 2455-2460.

[32] Zhou, J. H.; Kang, Q.; Xu, S. C.; Li, X. G.; Liu, C.; Ni, L.; Chen, N N.; Lu, C. L.; Wang, X. Z.; Peng, L. M. et al. Ultrahigh rate capability of $1 \mathrm{D} / 2 \mathrm{D}$ polyaniline/titanium carbide (MXene) nanohybrid for advanced asymmetric supercapacitors. Nano Res. 2022, 15,285-295.

[33] Salles, P.; Quain, E.; Kurra, N.; Sarycheva, A.; Gogotsi, Y. Automated scalpel patterning of solution processed thin films for fabrication of transparent MXene microsupercapacitors. Small 2018, 14,1802864

[34] Li, W.; Li, X. F.; Chang, W.; Wu, J.; Liu, P. F.; Wang, J. J.; Yao, X.; $\mathrm{Yu}, \mathrm{Z}$. Z. Vertically aligned reduced graphene oxide $/ \mathrm{Ti}_{3} \mathrm{C}_{2} \mathrm{~T}_{x}$ MXene hybrid hydrogel for highly efficient solar steam generation. Nano Res. 2020, 13, 3048-3056.

[35] Dillon, A. D.; Ghidiu, M. J.; Krick, A. L.; Griggs, J.; May, S. J.; Gogotsi, Y.; Barsoum, M. W.; Fafarman, A. T. Highly conductive optical quality solution-processed films of 2D titanium carbide. $A d v$. Funct. Mater. 2016, 26, 4162-4168.

[36] Halim, J.; Cook, K. M.; Naguib, M.; Eklund, P.; Gogotsi, Y.; Rosen, J.; Barsoum, M. W. X-ray photoelectron spectroscopy of select multilayered transition metal carbides (MXenes). Appl. Surf. Sci. 2016, 362, 406-417.

[37] Qin, L. Q.; Jiang, J. X.; Tao, Q. Z.; Wang, C. F.; Persson, I.; Fahlman, M.; Persson, P. O. Å.; Hou, L. T.; Rosen, J.; Zhang, F. L. A flexible semitransparent photovoltaic supercapacitor based on water-processed MXene electrodes. J. Mater. Chem. A 2020, 8, 5467-5475.

[38] Granqvist, C. G. Electrochromics for smart windows: Oxide-based thin films and devices. Thin Solid Films 2014, 564, 1-38.

[39] Niklasson, G. A.; Granqvist, C. G. Electrochromics for smart windows: Thin films of tungsten oxide and nickel oxide, and devices based on these. J. Mater. Chem. 2007, 17, 127-156.

[40] Inaba, M.; Iriyama, Y.; Ogumi, Z.; Todzuka, Y.; Tasaka, A. Raman study of layered rock-salt $\mathrm{LiCoO}_{2}$ and its electrochemical lithium deintercalation. J. Raman Spectrosc. 1997, 28, 613-617.

[41] Flores, E.; Novák, P.; Berg, E. J. In situ and operando Raman spectroscopy of layered transition metal oxides for Li-ion battery cathodes. Front. Energy Res. 2018, 6, 82 . 